\title{
Tracheostomy in COVID Times
}

\author{
Yatin Mehta ${ }^{1}$ Gaurav Kochar ${ }^{1}$ \\ ${ }^{1}$ Department of Anesthesiology and Critical Care, Medanta - The \\ Medicity, Gurugram, India528283
}

J Card Crit Care 2021;5:82-83.

Tracheostomy is a well-established procedure which is performed in critically ill adults requiring prolonged invasive ventilation. Transoral endotracheal tubes are poorly tolerated, have risk of dislodgement, require more sedation, and limits movement and communication, while tracheostomy has been shown to improve patient comfort and facilitate weaning and better respiratory tract toilet. The common indications of tracheostomy in ICU are prolonged ventilation weaning from ventilator support, tracheobronchial toileting and secretion management, upper airway obstruction and permanent airway control in malignancies, trauma or neurological conditions. Although a commonly performed procedure, certain questions about tracheostomy such as optimum timing and selection of patients still remain to be fully resolved.

The COVID pandemic has not only led to the emergence of a multitude of new issues but has also challenged established practices. For example, fear of intubation, state of" happy hypoxia," possibility of different pathophysiology, etc. were all such factors which might have impacted the decision to intubate many COVID patients. Tracheostomy in COVID patients is another such area where medical fraternity was hauled "back to square one" in many ways. Questions challenging otherwise established opinions and practices regarding the need for, safety, optimum method and timing, and safest method of tracheostomy have resurfaced in the context of COVID.

As per one estimate from the US, $>20 \%$ of hospitalized COVID patients needed intubation at least once. ${ }^{1}$ Studies from other researchers indicate that 10 to $15 \%$ of hospitalized COVID patients require mechanical ventilation. ${ }^{2-4} \mathrm{~A}$ significant proportion of intubated COVID patients have been reported to need prolonged ventilation. ${ }^{1}$ Addressing the role of tracheostomy in COVID patients is therefore a very logical step.

Tracheostomy is a known aerosol-generating procedure. Data from SARS-CoV-1 epidemic points toward increased
Address for correspondence Yatin Mehta, MD, Department of Anesthesiology and Critical Care, Medanta - The Medicity, Gurugram, India (e-mail: yatinmehta@gmail.com).

risk of viral transmission, with an odds ratio of $4: 2$ during tracheostomy. ${ }^{5}$

In case of COVID-19, data from multiple studies suggest no increase in health care personnel infection when enhanced personal protection equipment (PPE) precautions, including eye protection, powered air-purifying respirators (PAPR)/N95 mask, fluid-repellent disposable surgical gown, and gloves, are used during tracheostomy.-8 Tracheostomy by the most experienced operator, minimization of number of staff, and negative pressure operating room are additional precautions which should be taken.

No particular technique of tracheostomy has been recommended for COVID patients as of now. Between surgical and percutaneous tracheostomy, the latter usually requires more frequent disconnection of ventilator circuit; however, sufficient data to recommend surgical over percutaneous technique is not available. Use of sealed ventilator circuits and single-use bronchoscopes should be preferred. Performance of procedure under deep sedation and paralysis avoids coughing and complications and distraction due to patient movement, with resultant prolongation of procedure. Pausing ventilation during insertion of the tracheostomy tube can minimize aerosol spread; however, risk of desaturation during brief apnea should be evaluated beforehand. Percutaneous ultrasound is an alternative method of guidance for percutaneous tracheostomy which avoids aerosol generation. ${ }^{9}$

The insertion of a tracheostomy after around 7 to 10 days of invasive mechanical ventilation is generally considered a standard of care, due to potential to reduce the duration of mechanical ventilation and length of stay (LOS) in intensive care $^{10,11}$

Early tracheostomy has the potential advantage of shortening duration of ventilation and sedation, thereby enabling a more efficient use of mechanical ventilators, ICU beds and other resources. Median time from hospital admission to death in COVID has been reported to vary from 3 to 11 days; published online

August 5, 2021
DOI https://doi.org/

$10.1055 / \mathrm{s}-0041-1732837$

ISSN 2457-0206 (c) 2021. Official Publication of The Simulation Society (TSS), accredited by International Society of Cardiovascular Ultrasound (ISCU).

This is an open access article published by Thieme under the terms of the Creative Commons Attribution-NonDerivative-NonCommercial-License, permitting copying and reproduction so long as the original work is given appropriate credit. Contents may not be used for commercial purposes, or adapted, remixed, transformed or built upon. (https://creativecommons.org/licenses/by-nc-nd/4.0/). Thieme Medical and Scientific Publishers Pvt. Ltd. A-12, 2nd Floor, Sector 2, Noida-201301 UP, India 
therefore, it seems prudent to delay tracheostomy until patient has started improving and prognosis is clearer before doing a tracheostomy. This not only avoids futile tracheostomy and associated risk of exposure to staff but also enables a more secure airway (oropharyngeal vs. transtracheal) in case patient requires proning.

The American Academy of Otolaryngology-Head and Neck Surgery currently recommends that tracheostomy should not be performed prior to 14 days of endotracheal intubation. ${ }^{12}$

Moreover, some data points toward possibility of increased mortality in patients in whom tracheostomy is done earlier than 14 days. ${ }^{13}$

Initial studies have shown that viral loads from nasal and throat swabs were highest in the early phase of the disease, with clearance by days 9 to $15 .{ }^{14,15}$

The evidence thus far in terms of viral load risk would suggest that delaying tracheostomy to at least 14 days postintubation would represent the safest possible balance. ${ }^{15}$

In conclusion, tracheostomy has an important role to play in management of COVID patients who need ventilator. If conducted with all precautions and little modifications, it is safe for both operator and the patient.

Little is known about early versus late tracheostomy in pediatric patients. In this issue, there are two interesting papers from All India Institute of Medical Sciences (AIIMS) cardiac surgery population over a 1 -year period. They found that the early tracheostomy group ( $<7$ days) had significantly reduced hospital LOS, sepsis, ventilator-associated pneumonia (VAP), and escalation of antibiotics and antifungals. They also had reduced ICU LOS, lesser enteral nutrition (EN) interruptions, and ventilator days. This was a large population 41/1084 patients and is a significant finding.

In the same cohort, in a separate paper, the authors studied risk factors for nonsurvival. They found that lower $\mathrm{pH}$ $\mathrm{SPO}_{2}$, platelet count, and higher $\mathrm{S}$. lactate and random blood sugar (RBS) were risk factors for mortality.

Although cardiac surgical patients are clean, elective cases and the same conclusions may not be extrapolated to medical ICU. These are still significant findings.

\section{Conflict of Interest}

None declared.

\section{References}

1 Argenziano MG, Bruce SL, Slater CL, et al. Characterization and clinical course of 1000 patients with coronavirus disease 2019 in New York: retrospective case series. BMJ 2020;369:m1996
2 Wang D, Hu B, Hu C, et al. Clinical characteristics of 138 hospitalized patients with 2019 novel Coronavirus-infected pneumonia in Wuhan, China. JAMA 2020;323(11):1061-1069

3 Richardson S, Hirsch JS, Narasimhan M, et al. the Northwell COVID-19 Research Consortium. Presenting characteristics, comorbidities, and outcomes among 5700 patients hospitalized with COVID-19 in the New York City area. JAMA 2020;323(20):2052-2059

4 Docherty $A B$, Harrison EM, Green CA, et al. ISARIC4C investigators. Features of 20133 UK patients in hospital with covid-19 using the ISARIC WHO Clinical Characterisation Protocol: prospective observational cohort study. BMJ 2020;369:m1985

5 Tran K, Cimon K, Severn M, Pessoa-Silva CL, Conly J. Aerosol generating procedures and risk of transmission of acute respiratory infections to healthcare workers: a systematic review. PLoS One 2012;7(4):e35797

6 JAMA Otolaryngol Head Neck Surg Avilés-Jurado FX, Prieto-Alhambra D, González-Sánchez N. 2021;147(1):41-48

7 Yokokawa T, Ariizumi Y, Hiramatsu M, et al. Management of tracheostomy in COVID-19 patients: The Japanese experience. Auris Nasus Larynx 2021;48(3):525-529

8 Kim EJ, Yoo EH, Jung CY, Kim KC. Experience of percutaneous tracheostomy in critically ill COVID-19 patients. Acute Crit Care 2020;35(4):263-270

9 Mehta Y. Percutaneous dilatational tracheostomy: Guided well with real-time ultrasound. Indian J Crit Care Med 2013;17(6):335-336

10 Griffiths J, Barber VS, Morgan L, Young JD. Systematic review and meta-analysis of studies of the timing of tracheostomy in adult patients undergoing artificial ventilation. BMJ 2005;330(7502):1243

11 Adly A, Youssef TA, El-Begermy MM, Younis HM. Timing of tracheostomy in patients with prolonged endotracheal intubation: a systematic review. Eur Arch Otorhinolaryngol 2018;275(3):679-690

12 American Academy of Otolaryngology and Head and Neck Surgery. AAO position statement: tracheotomy recommendations during the COVID-19 pandemic. Available at: https:// www.entnet.org/content/aao-position-statement-tracheotomy-recommendations-during-covid-19-pandemic. Accessed June 1, 2020

13 Tang Y, Wu Y,Zhu F, et al. Tracheostomy in 80 COVID-19 Patients: A Multicenter, Retrospective, Observational Study. Front Med (Lausanne 2020;7:615845

14 Zou L, Ruan F, Huang M, et al. SARS-CoV-2 viral load in upper respiratory specimens of infected patients. $\mathrm{N}$ Engl J Med 2020;382(12):1177-1179

15 Lescure FX, Bouadma L, Nguyen D, et al. Clinical and virological data of the first cases of COVID-19 in Europe: a case series. Lancet Infect Dis 2020;20(6):697-706 